\title{
Postsynaptic Protein Kinase A Reduces Neuronal Excitability in Response to Increased Synaptic Excitation in the Drosophila CNS
}

\author{
Richard A. Baines \\ Neuroscience Group, Department of Biological Sciences, University of Warwick, Coventry, CV4 7AL, United Kingdom
}

\begin{abstract}
Previous work has identified a role for synaptic activity in the development of excitable properties of motoneurons in the Drosophila embryo. In this study the underlying mechanism that enables two such neurons, termed aCC and RP2, to respond to increased exposure to synaptic excitation is characterized. Synaptic excitation is increased in genetic backgrounds that lack either a cAMP-specific phosphodiesterase (EC:3.1.4, dunce) or acetylcholinesterase (EC:3.1.1.7, ace), the enzyme that terminates the endogenous cholinergic excitation of these motoneurons. Analysis of membrane excitability in aCC/RP2, in either background, shows that these neurons have a significantly reduced capability to fire action potentials (APs) in response to injection of depolarizing current. Analysis of underlying voltage-gated currents show that this effect is associated with a marked reduction in magnitude of the voltage-dependent inward $\mathrm{Na}^{+}$current $\left(I_{\mathrm{Na}}\right)$. Partially blocking $I_{\mathrm{Na}}$ in these motoneurons, using low concentrations of TTX, demonstrates that a reduction of $I_{\mathrm{Na}}$ is, by itself, sufficient to reduce membrane excitability. An analysis of firing implicates an increased AP threshold to underlie the reduction in membrane excitability observed because of heightened exposure to synaptic excitation. Genetic or pharmacological manipulations that either elevate cAMP or increase protein kinase A (PKA) activity in wild-type aCC/RP2 mimic both the reductions in membrane excitability and $I_{\mathrm{Na}}$. In comparison, increasing cAMP catabolism or inhibition of PKA activity is sufficient to block the induction of these activitydependent changes. The induced changes in excitability can be rapid, occurring within 5 min of exposure to a membrane-permeable cAMP analog, indicative that threshold can be regulated in these neurons by a post-translational mechanism that is dependent on phosphorylation.
\end{abstract}

Key words: aCC; cAMP; homeostasis; neural activity; RP2; synaptic development

\section{Introduction}

The acquisition of appropriate electrical properties is essential for the correct functioning of a neuron. Comparison of neurons grown in cell culture with that of their counterparts in vivo indicates that, although some aspects of this developmental program are autonomous, other aspects are dependent on external factors (Turrigiano et al., 1994; Spitzer et al., 2000, 2002). For example, the electrical development of chick ciliary ganglion neurons and Xenopus motoneurons is also dependent on target-derived trophic factors (Nick and Ribera, 2000; Cameron et al., 2001). The maturation of motoneurons in rat spinal cord is delayed in the presence of tetrodotoxin (TTX; Xie and Ziskind-Conhaim, 1995), whereas rat cortical neurons maintained in cell culture respond to changing exposure to synaptic depolarization by alteration of intrinsic excitability (Turrigiano et al., 1998; Desai et al., 1999). Experimental manipulation indicates that such cells are able to regulate their intrinsic excitability by one of a number

\footnotetext{
Received June 6, 2003; revised Aug. 4, 2003; accepted Aug. 4, 2003.

This study was funded by grants from the Wellcome Trust and Royal Society. I am very grateful to J. Jaynes and $M$. Fujioka for generously sharing RN2-0 GAL4 flies. I also acknowledge G. Davies, D. O'Dowd, J. Keiger, M. Suster, T. Zars, and C.-F. Wu for providing flies. I thank N. Dale and M. Wall for comments.

Correspondence should be addressed to Dr. R. A. Baines, Department of Biological Sciences, University of Warwick, Coventry, CV4 7AL, UK. E-mail: RBaines@bio.warwick.ac.uk.

Copyright $\odot 2003$ Society for Neuroscience $\quad$ 0270-6474/03/238664-09\$15.00/0
}

of mechanisms, which include changes in postsynaptic receptor density and/or kinetics (O'Brien et al., 1998; Turrigiano et al., 1998 ) and changes in postsynaptic voltage-gated ionic conductances (Turrigiano et al., 1995; Desai et al., 1999).

An ability to match neuronal excitability in response to fluctuating synaptic excitation is clearly advantageous when activity levels are changing rapidly, for example during embryonic neuronal circuit formation (Turrigiano, 1999; Turrigiano and Nelson, 2000). A number of hypotheses have been advanced to explain the functional basis of these compensatory mechanisms. The most attractive of these is that of $\mathrm{Ca}^{2+}$ entry, through postsynaptic glutamate receptors, acting as a molecular indicator of synaptic excitation (Liu et al., 1998; Turrigiano et al., 1998; Golowasch et al., 1999; Turrigiano, 1999). Manipulation of postsynaptic glutamate receptors at the Drosophila neuromuscular junction (NMJ) lends support for this hypothesis by demonstrating that such manipulations are sufficient to evoke homeostatic compensation (Davis et al., 1998; DiAntonio et al., 1999). However, genetically induced hyperpolarization of Drosophila muscle is also sufficient to evoke a compensatory increase in the release of presynaptic neurotransmitter that is independent of postsynaptic glutamate channel activity (Paradis et al., 2001). Regardless of the precise mechanism, it is implicit that the postsynaptic cell is able to monitor effectively the sum synaptic 
excitation to which it is exposed and to initiate compensatory mechanisms when this measure exceeds a predetermined range (for review, see Turrigiano, 1999; Davis and Bezprozvanny, 2001). It remains to be determined, however, how this measure of excitation is transduced.

A recent study in Drosophila has shown that the electrical development of identified motoneurons is perturbed similarly in the absence of synaptic transmission. When synaptic release is blocked, these motoneurons develop with significantly elevated voltage-gated $\mathrm{Na}^{+}$current $\left(I_{\mathrm{Na}}\right)$ and potassium current $\left(I_{\mathrm{K}}\right)$, changes that increase intrinsic membrane excitability (Baines et al., 2001). Restoration of normal synaptic function is sufficient to reverse these changes, demonstrating an ability of these neurons to regulate their own intrinsic excitability in response to changing synaptic excitation. The present study addresses the involvement of the cAMP-mediated signaling system in the regulation of intrinsic membrane excitability in these neurons. Using well characterized mutations that either increase the intracellular levels of cAMP in all neurons (dunce) or potentiate cholinergic neurotransmission (ace), together with transgenes that either mimic or inhibit the activity of protein kinase A (PKA), I show that increased cAMP or PKA activity is sufficient to reduce significantly, and rapidly, membrane excitability in identified motoneurons, an effect that results from an underlying reduction in $I_{\mathrm{Na}}$.

\section{Materials and Methods}

Fly stocks. Flies were fed on apple juice agar supplemented with yeast. Wild type was Canton S. RN2-O GAL4 (homozygous viable, second chromosome insert) was used to express selectively the UAS-driven transgenes in aCC and RP2 (this GAL4 insert is similar to, but strongerexpressing than, RRK-GAL4 used in previous studies; see Fujioka et al., 1999; Baines et al., 2002). Expression of RN2-O GAL4 begins in earlystage 16 embryos, a stage that precedes the onset of synaptogenesis (see Baines and Bate, 1998). Levels of cAMP were increased pan-neuronally by using two different and well characterized alleles of $d n c$, a cAMPspecific phosphodiesterase (EC:3.1.4; Dudai et al., 1976; Davis et al., 1995). cAMP levels were elevated in specific neurons by expression of UAS-rut (a type I $\mathrm{Ca}^{2+}$ /calmodulin-dependent adenylate cyclase; Zars et al., 2000). PKA activity was promoted by using UAS-PKAact ${ }^{1}$ and inhibited by using UAS-PKAinh ${ }^{1}$ (formerly termed PKA ${ }^{\text {BDK22) }}$; these transgenes are described in Davis et al. (1998). PKA also was inhibited by the expression of UAS-PKIF5.1, which codes for the N-terminal domain (residues 1-31) of rabbit skeletal muscle PKAc inhibitor protein (Kiger et al., 1999). The lethal $A c e^{J 50}$ (maintained over TM3 Ser for experiments shown in Fig. 4 or TM3 Ser Act:GFP in Fig. 7) mutation of acetylcholine esterase was used to increase exposure of developing neurons to acetylcholine (ACh; Greenspan, 1980). Homozygous mutant embryos were identified by a characteristic tremor phenotype and by the absence of green fluorescent protein (GFP; see Fig. 7).

Embryo dissection. Larvae were dissected and central neurons accessed as described in Baines and Bate (1998). The larva was viewed with a water immersion lens (total magnification, $800 \times$ ) combined with Nomarski optics (BX51 WI microscope, Olympus Optical, Tokyo, Japan).

Electrophysiology. All recordings, other than those that used ace alleles, were performed in young first instar larvae, 1-4 hr after hatching, at room temperature $\left(22-24^{\circ} \mathrm{C}\right)$. Recordings from ace embryos, which are homozygous lethal, were made at late-stage 17 (19-21 hr after egg laying at $25^{\circ} \mathrm{C}$ ). Whole-cell recordings (current and voltage clamp) were achieved by using thick-walled borosilicate glass electrodes (GC100TF10, Harvard, Edenbridge, UK) fire-polished to resistances between 15 and $20 \mathrm{M} \Omega$. Both current- and voltage-clamp recordings were made with an Axopatch-1D amplifier controlled by pClamp 8.1 (Axon Instruments, Foster City, CA). Only cells with an input resistance $>1$ G $\Omega$ were accepted for analysis. Current traces were filtered at $2 \mathrm{kHz}$ and sampled at $20 \mathrm{kHz}$. Membrane excitability was determined in current clamp by injection of a pulse of constant depolarizing current (1-20 pA/500 msec) from a maintained holding potential of $-60 \mathrm{mV}$. Voltage-clamp recordings of whole-cell currents were performed as described in Baines and Bate (1998). Briefly, voltage steps of $15 \mathrm{mV}$ increments were applied to cells from a conditioning potential of $-90 \mathrm{mV}$ (steps ranged from -60 to $+45 \mathrm{mV}$ ). For $\mathrm{K}^{+}$and $\mathrm{Ca}^{2+}$ currents a linearly scaled leak current obtained by hyperpolarizing conditioning steps (from -60 to $-90 \mathrm{mV}$ ) applied before any depolarizing steps was subtracted from each current trace with pClamp. To resolve $\mathrm{Na}^{+}$currents better, I used an on-line leak subtraction protocol $(\mathrm{P} / 4)$. Currents shown are the averages of five trials for each cell. Spontaneous miniature currents were recorded in the presence of TTX (0.1 $\mu \mathrm{M}$; Alomone Labs, Jerusalem, Israel). Amplitudes of both evoked and miniature currents were measured with Mini Analysis 5.2.8 (Synaptosoft, Decatur, GA).

Solutions. External saline for dissection and current-clamp analysis of excitability consisted of (in mM): $135 \mathrm{NaCl}, 5 \mathrm{KCl}, 4 \mathrm{MgCl}_{2} \cdot 6 \mathrm{H}_{2} \mathrm{O}, 2$ $\mathrm{CaCl}_{2} .2 \mathrm{H}_{2} \mathrm{O}, 5 \mathrm{~N}$-Tris[hydroxymethyl]methyl-2-amonoethanesulfonic acid (TES), and 36 sucrose. For isolation of ionic currents for voltage clamp, the following solutions were used: $\mathrm{K}^{+}$isolation saline: $6 \mathrm{KCl}, 140$ Tris- $\mathrm{HCl}, 10 \mathrm{MgCl}_{2} .6 \mathrm{H}_{2} \mathrm{O}, 10$ HEPES, 10 glucose, $0.5 \mathrm{CaCl}_{2} .2 \mathrm{H}_{2} \mathrm{O}$; $\mathrm{Ca}^{2+}$ isolation saline: 50 Tris- $\mathrm{HCl}, 50 \mathrm{BaCl}_{2}, 5 \mathrm{KCl}, 50$ tetraethylammonium chlorides (TEA), 10 4-aminopyridine (4-AP), 10 HEPES, 10 glucose; $\mathrm{Na}^{+}$isolation saline: $100 \mathrm{NaCl}, 5 \mathrm{KCl}, 50$ TEA, 10 4-AP, 10 HEPES, 10 glucose, $0.5 \mathrm{CaCl}_{2} .2 \mathrm{H}_{2} \mathrm{O}$. All solutions were $\mathrm{pH} 7.15$.

Internal patch solution consisted of (in $\mathrm{mM}$ ): $140 \mathrm{~K}^{+}$-methylsulfonate $\left(\mathrm{KCH}_{3} \mathrm{SO}_{3}\right), 2 \mathrm{MgCl}_{2} \cdot 6 \mathrm{H}_{2} \mathrm{O}, 2$ EGTA, $5 \mathrm{KCl}, 20 \mathrm{HEPES}, \mathrm{pH}$ 7.4. When either $\mathrm{Ca}^{2+}$ or $\mathrm{Na}^{+}$currents in voltage clamp were recorded, $\mathrm{CsCl}_{2}$ was substituted for $\mathrm{KCH}_{3} \mathrm{SO}_{3}$.

Statistics. Data were compared by using a nonpaired Student's $t$ test. Results were deemed significant at ${ }^{\star} p \leq 0.05$ and ${ }^{\star *} p \leq 0.01$. All values shown are the mean \pm SE.

\section{Results}

In the absence of evoked release of neurotransmitter, the Drosophila motoneurons aCC and RP2 develop with significantly increased voltage-activated $I_{\mathrm{K}}$ and $I_{\mathrm{Na}}$, alterations that enhance membrane excitability (Baines et al., 2001). To determine whether these neurons are also capable of responding to enhanced levels of synaptic excitation, I adopted two approaches. First, embryos lacking a cAMP phosphodiesterase, known to result in potentiation of synaptic transmission at the NMJ (Zhong and $\mathrm{Wu}, 1991)$, were analyzed for central synaptic activity. Second, the endogenous cholinergic excitation of motoneurons (Baines et al., 2001) was potentiated by removal of ACh esterase.

\section{Mutations in dunce and ace result in enhanced synaptic excitation of motoneurons}

Recordings of synaptic currents in aCC/RP2 under voltage clamp $\left(V_{\mathrm{h}}-60 \mathrm{mV}\right)$ show large $(50-300 \mathrm{pA})$ inward currents that are relatively long-lived (500-1000 msec; Fig. 1A) (for a description of these synaptic inputs, see Baines et al., 1999, 2001). The nature of these currents, in particular their slow time course, is indicative that they result from the synchronous activity of multiple presynaptic inputs, the individual characteristics of which remain unknown. In the two $d n c$ alleles that were used in this study $\left(d n c^{l}\right.$ and $d n c^{2}$ ), the average amplitudes of synaptic currents recorded in aCC/RP2 are significantly greater than for WT $(88 \pm 2.8,96 \pm$ 5 , and $76 \pm 3.3 \mathrm{pA}$ for $d n c^{1}, d n c^{2}$, and WT, respectively; $p \leq 0.05$, $0.01 ; n \geq 10$; Fig. $1 B$ ). Frequency of synaptic currents was not significantly different (data not shown). Cumulative probability plots of individual synaptic currents show that there is a significant increase in the occurrence of larger amplitude currents in both $d n c$ alleles as compared with WT (Fig. 1C). In addition to an increase in synaptic excitation, the resting membrane potential (RMP) of aCC/RP2 in both $d n c$ alleles also was depolarized relative to WT (e.g., $-43.5 \pm 1.9 \mathrm{vs}-51.6 \pm 2.3 \mathrm{mV}$ for $d n c^{2}$ vs WT; $n \geq 10 ; p \leq 0.05$ ). 
There are a number of probable mechanisms that might underlie an increase in synaptic transmission under conditions of elevated cAMP. First, the postsynaptic sensitivity of aCC/RP2 to ACh may have increased. Second, the effect could be attributable to increased synaptic release of ACh from presynaptic terminals. Third, elevated cAMP might increase the number of presynaptic terminals. Fourth, increasing cAMP may better correlate the firing of the multiple presynaptic inputs to these neurons. To distinguish among some of these possibilities, I analyzed spontaneous currents (Fig. 1D). In the presence of 0.1 $\mu \mathrm{M}$ TTX the evoked release of neurotransmitter is blocked, leaving only that which is released by spontaneous fusion of single or a few vesicles. Comparison of these spontaneous currents, the amplitude of which are indicative of postsynaptic receptor function, between $d n c^{2}$ and WT show no significant differences in either amplitude distribution (Fig. 1E) or frequency (data not shown). This suggests that postsynaptic sensitivity to ACh is not altered in $d n c$. Further, the lack of change in frequency of spontaneous currents is consistent with there being no increase in the number of presynaptic terminals. Thus it would seem that, although the most probable cause for the increase in synaptic transmission observed in $d n c$ alleles is an increase in evoked release of $\mathrm{ACh}$, an increase in synchronous activity of the presynaptic inputs to these neurons cannot be ruled out.

The second approach used to potentiate synaptic excitation of motoneurons was to use embryos that lack functional ACh esterase (ace), the enzyme required to terminate cholinergic excitation of motoneurons in Drosophila (Baines et al., 2001). Embryos homozygous for the ace $e^{50}$

allele are lethal and, moreover, exhibit rapid and uncoordinated peristalsis, a phenotype predicted for a hyperexcitability mutant. Recordings from aCC/RP2 under voltage clamp show an apparent absence of well defined synaptic currents, instead showing numerous smaller currents as compared with WT. However, measurement of resting membrane potential in these neurons shows, similar to $d n c$, a significant depolarization as compared with WT $(-46.0 \pm 1.9$ vs $-51.6 \pm 2.3 \mathrm{mV}$ for ace vs WT, respectively; $p \leq 0.05 ; n \geq 8$ ). Thus it seems likely that the increase in cholinergic neurotransmission, which would be predicted to result from the loss of acetylcholinesterase (AChE), underlies the increased depolarization of resting membrane potential in aCC/RP2.

Increased exposure to synaptic excitation downregulates membrane excitability

The ability of aCC/RP2 to fire action potentials (APs; no differences were noted between each neuron) in response to an injection of constant current $(10 \mathrm{pA} / 500 \mathrm{msec})$ was determined in
D

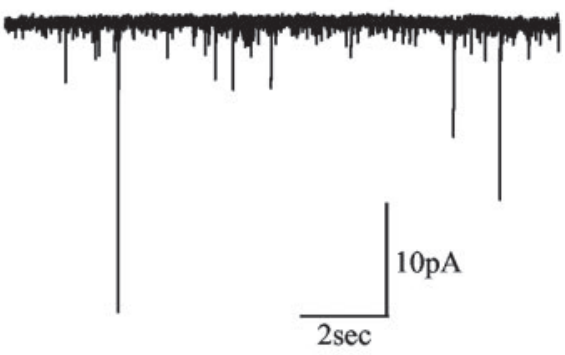

$\mathrm{C}$

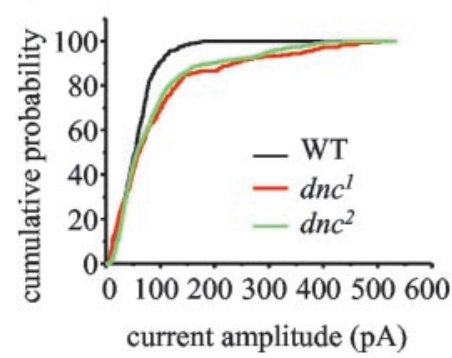

$\mathrm{E}$

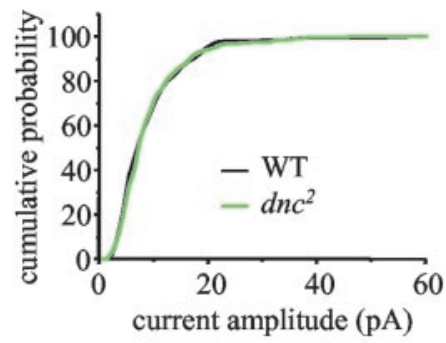

Figure 1. Synaptic excitation of aCC/RP2 is increased in $d n c$. Ai, Whole-cell voltage-clamp recordings $\left(V_{h}-60 \mathrm{mV}\right)$ from 1999, 2001). These currents are relatively long-lived, lasting for up to $400 \mathrm{msec}$ (see Aii). B, The average amplitude of excitatory secorded in aCC/RP2 is significantly greater in both $d n c^{7}$ and $d c^{2}$ relative to WT. ${ }^{*} p \leq 0.05$; ${ }^{* *} p \leq 0.01$. C, Cumulative probability plots of individual excitatory current amplitudes show that there is an increase in larger amplitude currents in both those currents that are elicited from the spontaneous release of vesicles in the presynaptic interneurons. $E$, Spontaneous current amplitudes in aCC/RP2 between WT and $d c^{2}$ are not significantly different.

$d n c^{1}, d n c^{2}, a c e$, and WT. In all cases the neurons were held at -60 $\mathrm{mV}$ by injection of a small amount of hyperpolarizing current to allow a direct comparison between excitability regardless of the true RMP observed in these respective genotypes (see above). The number of APs fired by aCC/RP2 was decreased significantly in both $d n c$ alleles (increased cAMP) as compared with WT ( $15 \pm 0.9$ and $16.5 \pm 1.6$ vs $23 \pm 0.8 \mathrm{APs}$ for $d n c^{l}, d n c^{2}$, and WT, respectively; $p \leq$ 0.01 for both $d n c$ alleles; $n \geq 10$; Fig. $2 A$ ). A more detailed analysis of individual APs shows no apparent differences in either AP duration (4.1 \pm 0.3 vs $4.0 \pm 0.6 \mathrm{msec}$ for WT vs $\left.d n c^{2} ; n=10\right)$ or amplitude $(13.4 \pm 1.2 \mathrm{vs} 13.1 \pm 1.7 \mathrm{mV}$, respectively; $n=10)$. Measurement of the time taken for successive APs to reach peak amplitude is, however, significantly greater in $d n c^{2}$ as compared with WT (36.7 \pm 3.5 vs $22.8 \pm 1.1 \mathrm{msec}$ for WT vs $d n c^{2} ; n=10 ; p<0.01 ;$ Fig. $\left.2 B\right)$. Input resistance, changes in which could result in altered excitability of aCC/RP2, was unchanged (7.4 \pm 0.9 vs $6.9 \pm 0.8 \mathrm{G} \Omega$ for WT vs $d n c^{2}$; $n \geq 17 ; p>0.05)$.

Comparison of membrane excitability of aCC/RP2 in ace embryos shows a remarkably similar reduction to that observed in 

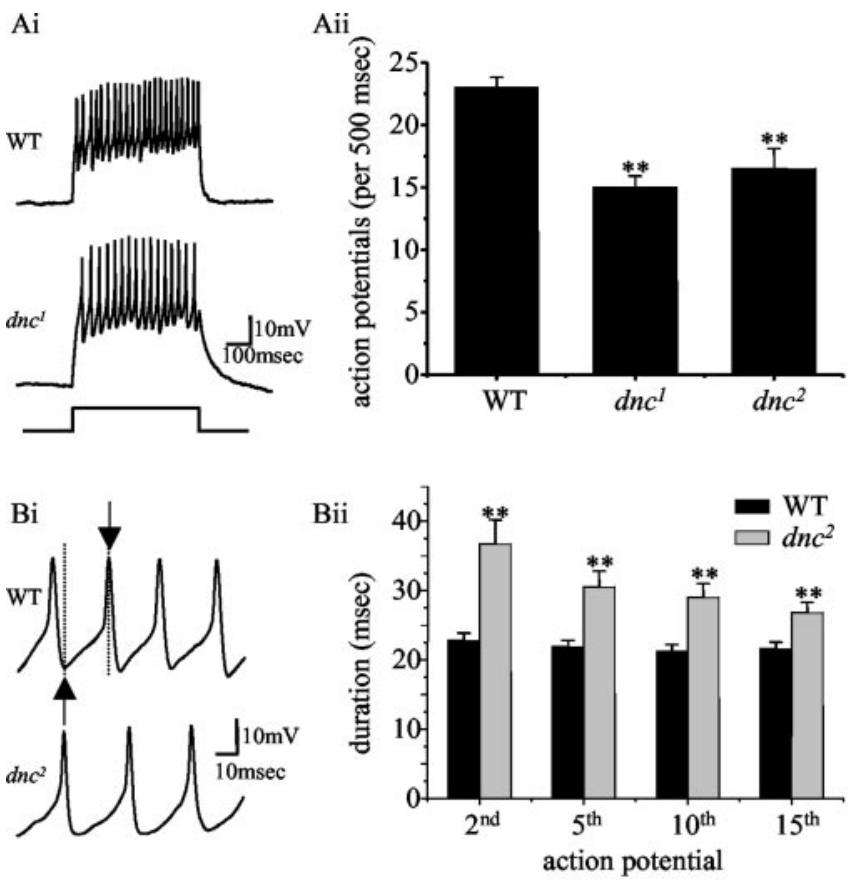

$\mathrm{Ci}$ Cii
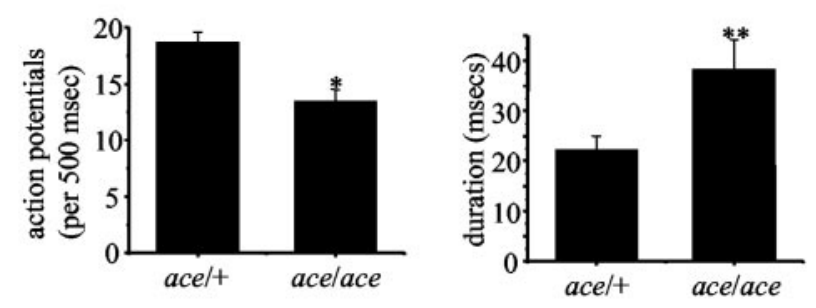

Figure 2. Membrane excitability of aCC/RP2 is reduced in both $d n c$ and ace. Ai, Injection of depolarizing current $(10 \mathrm{pA} / 500 \mathrm{msec})$ is sufficient to fire action potentials in aCC/RP2. Aii, Averaged APs fired in response to depolarizing current (10 pA/500 msec) show a significant reduction in both $d n c^{1}$ and $d n c^{2}$ as compared with WT ( $\left.p \leq 0.01\right)$. Bi, The duration between successive APs, measured from the peak of the preceding afterhyperpolarization to the peak of depolarization (shown by arrows and dotted lines), is increased significantly in $d n c^{2}$ as compared with WT. Bii, AP duration is consistently longer in $d n c^{2}$ as compared with WT, regardless of which AP is measured. Shown is the average inter-AP duration for the 2nd, 5th, 10th, and 15 th AP to be fired by the depolarizing current pulse. Ci, Injection of constant current (10 pA/500 $\mathrm{msec}$ ) also results in fewer APs being fired in aCC/RP2 in ace late-stage 17 embryos (19-21 hr after egg laying) as compared with heterozygous controls. (iii, Similar to the effect seen in $d n c$, the duration between successive APs also is increased significantly in ace mutants. ${ }^{*} p \leq 0.05$; ${ }^{* *} p \leq 0.01$.

both alleles of $d n c$ (Fig. 2Ci). Thus over-exposure to ACh results in significantly fewer APs being fired in response to injection of constant current from a maintained RMP of $-60 \mathrm{mV}(13.5 \pm 1.0$ vs $18.7 \pm 0.9 \mathrm{APs} / 500 \mathrm{msec}$ for ace vs ace/ $+; n \geq 8 ; p \leq 0.05)$. Similarly, the time taken for successive APs to reach peak amplitude was increased significantly $(38.4 \pm 5.8 \mathrm{vs} 22.2 \pm 2.8 \mathrm{msec}$ for ace vs ace/ $+; n=6 ; p<0.01$; Fig. 2Cii), whereas amplitude and duration were not affected (data not shown). Thus in two different genetic backgrounds in which synaptic depolarization of aCC/RP2 is either clearly increased $(d n c)$ or inferred to be increased (ace), these neurons exhibit a significantly reduced capability to fire APs in response to current injection.

Decreased membrane excitability is associated with a reduction in $I_{\mathrm{Na}}$

When aCC/RP2 develop in the absence of synaptic excitation, they exhibit an increased membrane excitability that is associated
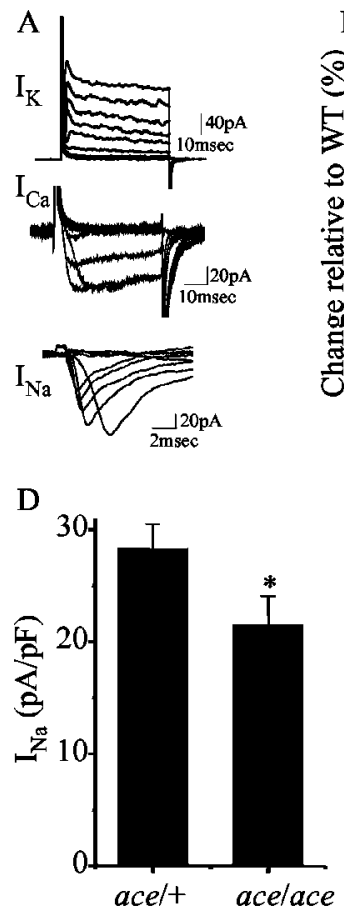

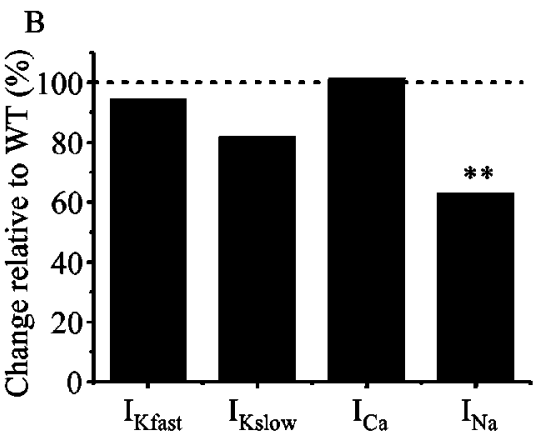

C

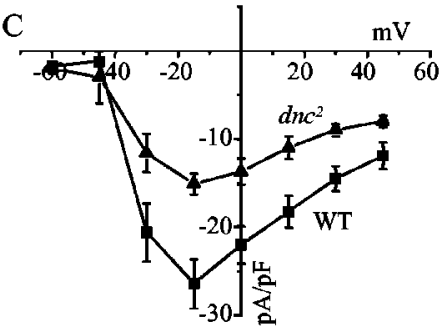

$\mathrm{E}$

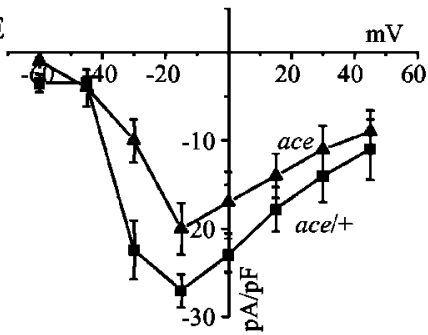

Figure 3. $I_{\mathrm{Na}}$ is reduced significantly in aCC/RP2 in both $d n$ c and ace mutants. $A$, Whole-cell voltage-clamp analysis in aCC/RP2 reveals the presence of at least two outward $\mathrm{K}^{+}$conductances $\left(I_{\text {Kfast }}\right.$ and $I_{\text {Kslow }}$ ), inward $\mathrm{Ca}^{2+}$, and inward Na ${ }^{+}$currents (for a complete description of these currents, see Baines and Bate, 1998). B, The current density of $/{ }_{\mathrm{Na}}$ is reduced significantly in $d c^{2}$ as compared with WT. Magnitude of the other currents is not significantly different from WT. Shown are WT currents that have been normalized to $100 \%$ (dashed line; actual values:WT, $77.4 \pm 9.2,69.8 \pm 9.5,21.0 \pm 1.6,28.0 \pm 2.6 \mathrm{pA} / \mathrm{pF} ; \mathrm{dnc}^{2}, 73.0 \pm 4.5,57.1 \pm 3.9,21.3 \pm$ $3.3,17.6 \pm 1.4 \mathrm{pA} / \mathrm{pF}$ for $I_{\text {Kfast }}, I_{\mathrm{Kslow}}, I_{\mathrm{Ca}}$, and $I_{\mathrm{Na}}$, respectively). ${ }^{*} p \leq 0.01$. C, Currentvoltage plots of $I_{\mathrm{Na}}$ in both WT and $d n c^{2}$ show a reduction in current magnitude at all voltages above activation. Moreover, the membrane potential at which this current activates is not significantly different. $D$, The magnitude of / $_{\mathrm{Na}}$ in aCC/RP2 also is reduced significantly in acelate-stage 17 embryos as compared with heterozygous controls. ${ }^{*} p \leq 0.05 . E$, A plot of current-voltage relationships indicates no change in voltage dependence of $I_{\mathrm{Na}}$ in ace as compared with WT.

with an underlying increase in voltage-dependent $I_{\mathrm{Na}}$ (Baines et al., 2001). It might be predicted, therefore, that a decrease in membrane excitability, produced as a result of increased exposure to synaptic excitation, will involve a reduction of $I_{\mathrm{Na}}$. A voltage-clamp analysis of voltage-dependent currents in aCC/ RP2 (Fig. 3A,B) (which do not significantly differ between aCC and RP2; Baines et al., 2001) shows a marked 38\% reduction in peak current density of $I_{\mathrm{Na}}$ in $d n c^{2}$ as compared with WT (17.6 \pm 1.4 vs $28 \pm 2.6 \mathrm{pA} / \mathrm{pF} ; p \leq 0.01 ; n \geq 10)$. Of the other voltagegated currents that were analyzed, $I_{\mathrm{K}}$ (in particular the slow component of this current; see Baines et al., 2001) showed a small, but not significant, reduction, whereas $I_{\mathrm{Ca}}$ remained unaffected ( $p>$ 0.05; Fig. $3 B$ ). Cell capacitance was not different, indicative that cell size had not changed $\left(3.3 \pm 0.25\right.$ vs $3.5 \pm 0.25 \mathrm{pF}$ for $d n c^{2}$ vs $\mathrm{WT} ; p>0.05 ; n \geq 10)$. Analysis of current-voltage relationship $(I-V)$ for $I_{\mathrm{Na}}$ in WT and $d n c^{2}$ shows that current is reduced at all voltages above threshold. Indeed, the similarity in the shape of both plots is indicative that the reduction in current that was 

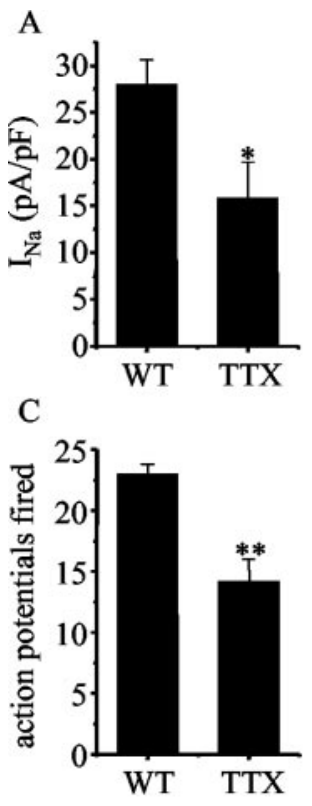

B

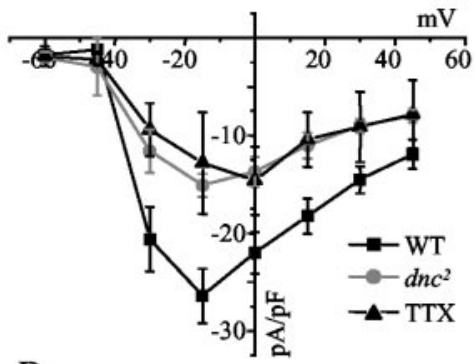

D
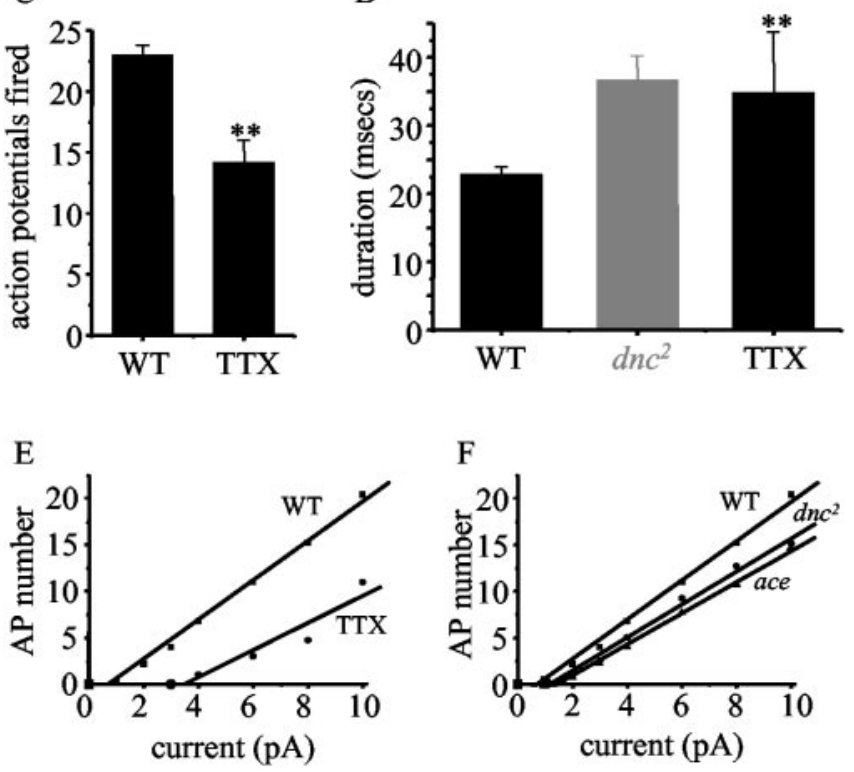

Figure 4. Reduction of $I_{\mathrm{Na}}$ is sufficient to suppress membrane excitability. $A$, The amplitude of $I_{\mathrm{Na}}$ recorded in aCC/RP2 is reduced significantly in the presence of a low concentration of $1 \mathrm{~nm}$ $\operatorname{TTX}\left(15.9 \pm 3.8\right.$ vs $28.0 \pm 2.6 \mathrm{pA} / \mathrm{pF} ; n \geq 5$; $\left.^{*} p \leq 0.05\right)$. $B$, Current-voltage plots indicate no change in voltage dependence. The current-voltage plot for $I_{\mathrm{Na}}$ recorded in $d n c^{2}$ is shown for comparison. $C$, In the presence of $1 \mathrm{~nm}$ TTX the number of APs fired by aCC/RP2 in response to depolarizing current $(10 \mathrm{pA} / 500 \mathrm{msec})$ is reduced significantly as compared with WT lacking this neurotoxin (14.2 \pm 1.8 vs $\left.23 \pm 0.8 \mathrm{APs} ; n \geq 5 ;{ }^{* *} p \leq 0.01\right)$. D, The duration between successive APs elicited by current injection is increased significantly as compared with controls. The increase in duration observed in $d n c^{2}$ is shown for comparison. Duration between the first and second APs to be fired is shown (see Fig. 2 Bi for an explanation of the measure that was used). ${ }^{* *} p \leq 0.01$. E, APs elicited by injection of constant current in aCC/RP2 in WT show a proportional increase with current strength $(0-10 \mathrm{pA} / 500 \mathrm{msec})$. An increased amount of current is required to elicit a comparable number of APs in the presence of $1 \mathrm{~nm}$ TTX. This shift to the right is indicative of an increased threshold for AP firing. F, Similar current-firing plots for $d n c^{2}$ and ace mutants show a similar, although reduced, shift to the right as compared with WT.

observed is not the result of changes in the voltage dependence of $I_{\mathrm{Na}}$ (Fig. $3 C$ ). A similar analysis of $I_{\mathrm{Na}}$ in aCC/RP2 in ace embryos shows an equally significant decrease in peak current density as compared with heterozygous controls $($ ace/,$+ 21.5 \pm 2.6$ vs $28.3 \pm 2.2 \mathrm{pA} / \mathrm{pF} ; n \geq 8 ; p \leq 0.05$; Fig. $3 D$ ). Current-voltage plots show no indication of a change in voltage dependence (Fig. $3 E$ ).

\section{An increase in AP threshold underlies the reduction of membrane excitability}

To test directly whether a reduction in $I_{\mathrm{Na}}$ is sufficient to suppress membrane excitability, I used TTX. In the presence of low concentrations of TTX $(1 \mathrm{nM}) I_{\mathrm{Na}}$ is reduced in aCC/RP2 by an amount similar to that seen in $d n c^{2}$ and ace (Fig. 4A,B). Under these conditions the number of APs fired by aCC/RP2 in response to depolarizing current (from a maintained RMP of $-60 \mathrm{mV}$ ) is reduced significantly as compared with controls that lack TTX
(14.2 \pm 1.8 vs $23 \pm 0.8$ APs; $n \geq 8 ; p \leq 0.01$; Fig. $4 C$ ). Again, similar to both $d n c$ and ace alleles (see above), the time required for successive APs to reach peak amplitude is increased significantly $(34.8 \pm 3.3$ vs $22.8 \pm 1.1$ msec for TTX vs WT; $n \geq 8 ; p<$ 0.01 ; Fig. $4 D)$. AP duration and amplitude are not altered significantly by the presence of this concentration of TTX $(3.7 \pm 0.35$ $\mathrm{msec} / 10 \pm 1.6 \mathrm{mV} ; n=10 ; p>0.05$; data not shown).

The most obvious mechanism by which TTX is able to reduce membrane excitability is one of increased threshold for AP firing, given that the threshold will be dependent on inward current carried by $I_{\mathrm{Na}}$. A prediction based on such a mechanism is that it would require a proportionately higher amount of injected current to produce an equal number of APs as compared with WT. Analysis of firing over a range of injected currents shows clearly that there is indeed an increase in the amount of current required after treatment with TTX (Fig. 4E). Analysis of AP-current relationships in aCC/RP2 in both $d n c^{2}$ and ace embryos shows a similar, although less marked, increase in required current to fire an equal number of APs as compared with WT (Fig. $4 F$ ). Thus these observations are consistent with a reduction in $I_{\mathrm{Na}}$, which results from overexposure to synaptic depolarization, reducing membrane excitability in aCC/RP2 by increasing AP threshold.

Increased cAMP or PKA activity suppresses action potential firing in aCC/RP2

Although it seems clear that aCC/RP2 neurons respond to increased synaptic excitation by reducing intrinsic membrane excitability, it is not clear how this signal is transduced within the cell. One obvious candidate highlighted by this study is the intracellular signaling molecule cAMP. To test for the involvement of cAMP, I selectively increased this molecule in just aCC/RP2 by expression of a UAS-rutabaga transgene driven by RN2-O GAL4 (see Materials and Methods; rutabaga encodes a calcium/ calmodulin-responsive adenylate cyclase). Expression of this transgene in aCC/RP2 suppresses the number of APs fired to the same extent as that observed in $d n c(14 \pm 0.9$ vs $26 \pm 2.9$ APs, 10 $\mathrm{pA} / 500$ msec; $p \leq 0.01 ; n \geq 8$; Fig. $5 A$ ). The effect of rut is mimicked by the expression of a constitutively active PKA $\left(P K A a c t^{l}\right)$ in aCC/RP2 (Fig. 5A,C). Expression of a dominantnegative form of PKA $\left(P K A i_{n h}{ }^{1}\right)$ was, however, without effect. Similarly, inhibition of PKA activity in aCC/RP2 by expression of a rabbit PKA inhibitor protein (UAS-PKIF5.1; Kiger et al., 1999) (see Materials and Methods) also failed to affect membrane excitability (data not shown). The selective expression of rut or $P K A a c t^{1}$ in aCC/RP2 is also sufficient to reduce $I_{\mathrm{Na}}$ significantly (Fig. 5B), supporting the hypothesis that activity-dependent regulation of this current is sufficient to alter endogenous excitability in these neurons. Thus genetic modifications that result in increased cAMP and/or PKA activity clearly mimic the changes in intrinsic membrane excitability observed after exposure to heightened levels of synaptic depolarization.

\section{Inhibition of cAMP or PKA is sufficient to block reduction in} $I_{\mathrm{Na}}$ and excitability

To demonstrate directly that increased synaptic depolarization is sufficient to reduce neuronal excitability via a mechanism that involves cAMP and activation of PKA, I blocked this signaling mechanism in aCC/RP2 in the ace mutant background. Specifically, UAS- $d n c$ (a cAMP-specific phosphodiesterase that catalyzes the catabolism of cAMP) and UAS-PKAinh ${ }^{1}$ were expressed in aCC/RP2 in the ace background. Expression of either transgene is sufficient to prevent both the reduction in $I_{\mathrm{Na}}$ (Fig. 6A) and the associated decrease in neuronal excitability normally ob- 

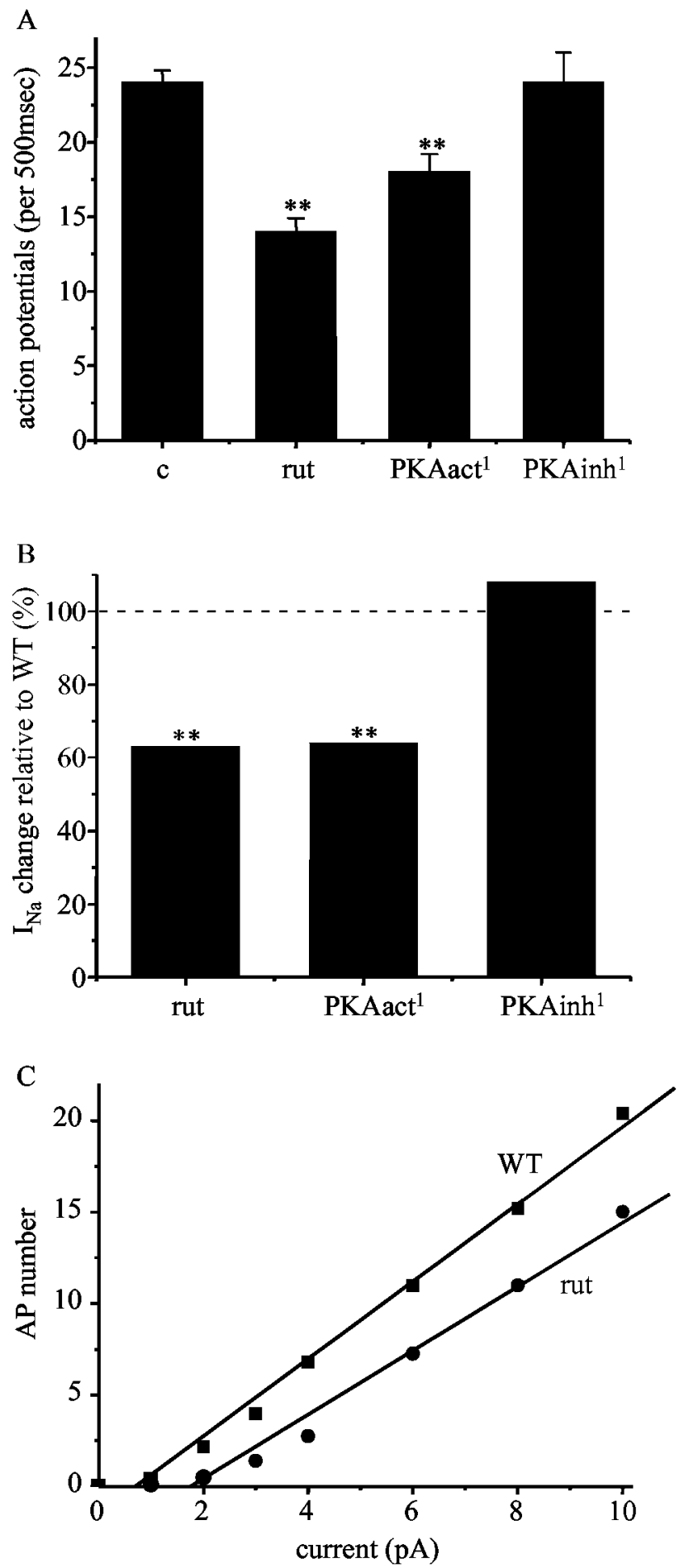

Figure 5. Postsynaptic CAMP/PKA activity is sufficient to reduce membrane excitability in aCC/RP2. A, Increasing CAMP in just aCC/RP2 by expression of UAS-rut (using RN2-0 GAL4) is sufficient to reduce membrane excitability in these neurons to an extent similar to that observed in the alleles of $d n c$ and ace (see Fig. 2). Expression of a constitutively active form of PKA (PKAact ${ }^{7}$ ) in just these two motoneurons is also sufficient to reduce membrane excitability. Inhibition of PKA $\left(P K A\right.$ inh $\left.^{7}\right)$, however, is without effect as compared with controls $(c$, parental stocks). B, Expression of UAS-rut (rut) or UAS-PKAact ${ }^{7}$ in aCC/RP2, but not UAS-PKAinh ${ }^{7}$, is also sufficient to reduce $I_{\mathrm{Na}}$ in these neurons as compared with WT, which has been set to $100 \%$ (dashed line; actual values are 17.6 $\pm 3.1,17.9 \pm 3.4,30.25 \pm 2.6,28.0 \pm 2.6 \mathrm{pA} / \mathrm{pF}$ for rut, PKAact ${ }^{1}$, PKAinh ${ }^{1}$, and WT, respectively). Values are the mean $\pm S E ; n \geq 8\left({ }^{* *} p \leq 0.01\right)$. C, Analysis of the effect of rut expression on current-firing properties in aCC/RP2 shows that expression of this transgene shifts the relationship to the right, indicative of an increased AP threshold.
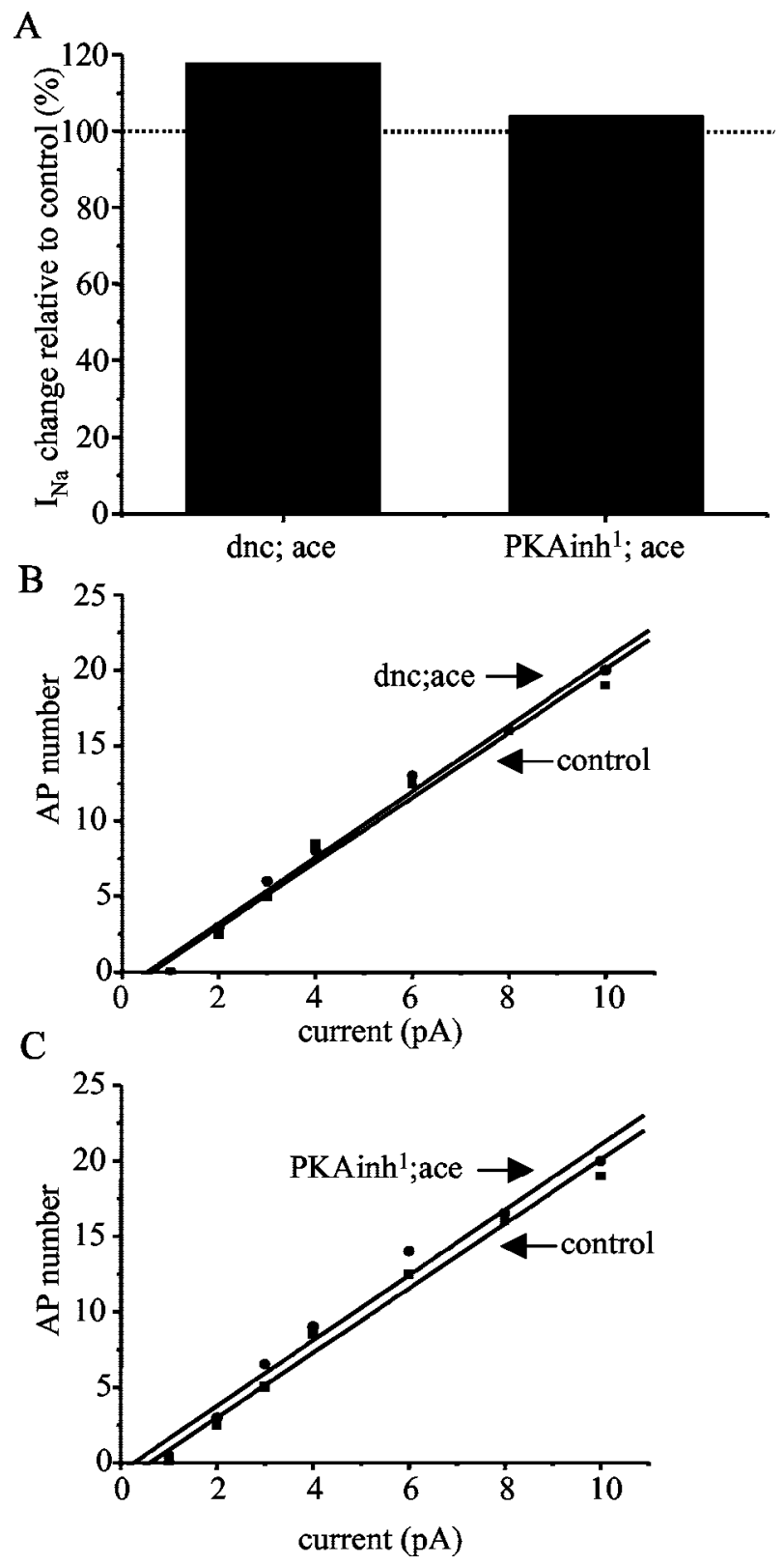

Figure 6. Blockade of CAMP/PKA activity is sufficient to prevent activity-dependent changes in excitability. A, Expression of either UAS-dnc or UAS-PKAinh ${ }^{7}$ in aCC/RP2 in an ace background prevents the activity-dependent reduction in $I_{\mathrm{Na}}$ normally seen in ace alone (compare with Fig. 3D). Actual values are $27 \pm 1.9$ versus $32 \pm 4.2 \mathrm{pA} / \mathrm{pF}$ for control versus $d n c ; a c e$ and $27 \pm 2.7$ versus $28 \pm 2.7 \mathrm{pA} / \mathrm{pF}$ for control versus PKAinh ${ }^{7} ;$ ace $(n=8$; mean $\pm \mathrm{SE} ; p>0.05)$. $B, C$, Expression of either $d n$ cor $P K A i n h^{1}$ in aCC/RP2 in an ace background is also sufficient to prevent the reduction in excitability observed in ace alone (compare with Fig. 4F). In all cases the controls consist of parental stocks.

served in these neurons in ace alone (Fig. 6B,C). However, although $I_{\mathrm{Na}}$ and excitability are rescued by the expression of either transgene, RMP remained depolarized relative to WT $(-45.4 \pm$ 1.8 and $-47.2 \pm 1.8 \mathrm{mV}$ for UAS- $d n c$ and UAS- PKAinh ${ }^{1}$, respectively; $n=8$ ). Thus although these neurons are exposed to heightened levels of synaptic depolarization, which may underlie the apparent increase in RMP, excitability remains unchanged. These results are therefore entirely consistent with, and moreover provide convincing evidence for, a mechanism that couples synaptic excitation to CAMP to regulate neuronal excitability in these neurons. 


\section{Alteration of membrane excitability is rapid}

The decrease in membrane excitability observed after genetic manipulations that increase cAMP/PKA activity in aCC/RP2 could result from either post-translational mechanisms or from altered gene expression. To distinguish between these two possibilities, I determined the time course required for elevated cAMP to suppress membrane excitability. To mimic the effect of increasing cAMP in these neurons, I used a membrane-soluble nonhydrolyzable form of this second messenger known to activate PKA (Sp-cAMPS). After just $5 \mathrm{~min}$ of exposure to Sp-cAMPS ( $0.5 \mathrm{mM})$ the membrane excitability of aCC/RP2 was reduced significantly as compared with WT controls $(11.8 \pm 2.7$ vs $23 \pm 0.8$ APs, 10 $\mathrm{pA} / 500 \mathrm{msec} ; p \leq 0.01 ; n \geq 8$; Fig. $7 A)$. A similar exposure to a membrane-soluble inhibitor of PKA (Rp-cAMPS; $0.5 \mathrm{~mm} / 5 \mathrm{~min}$ ) did not, however, affect membrane excitability (Fig. 7A).

A brief ( $5 \mathrm{~min}$ ) exposure to Sp-cAMPS ( $0.5 \mathrm{~mm}$; PKA activator $)$ is also sufficient to reduce $I_{\mathrm{Na}}$ in aCC/RP2 $(20 \pm 1.7 \mathrm{pA} / \mathrm{pF}$; $p \leq 0.01 ; n \geq 8$; Fig. $7 B)$ and to induce a shift in the current required to elicit APs (Fig. $7 C$ ). Inhibition of PKA with the use of Rp-cAMPS was, by comparison, without effect, mirroring the inability of PKA inhibition to increase membrane excitability in these neurons. Thus pharmacological manipulations that result in an increased activation of PKA mimic the effect of genetic manipulations that either elevate cAMP or increase PKA activity in aCC/RP2. It would seem, therefore, that the alteration to membrane excitability induced by elevated cAMP/PKA activity in aCC/RP2 can occur rapidly, indicative of post-translational regulation. An effect on gene expression resulting from chronic increases in cAMP/PKA activity cannot, however, be ruled out.

\section{Discussion}

Although it has been demonstrated previously that $I_{\mathrm{Na}}$ can be modulated by phosphorylation in a diverse range of animals (Gershon et al., 1992; Li et al., 1992; Smith et al., 1997; Wicher, 2001), a physiological understanding for such a mechanism has, until now, been lacking. The key finding of this study, that reduction in $I_{\mathrm{Na}}$ mediated by cAMP and its immediate downstream target PKA plays a key role in the mechanisms that regulate target excitability in response to presynaptic activity in a developing neuron, makes a significant contribution to closing this gap in our understanding. Thus Drosophila motoneurons exposed to increased synaptic excitation, known to increase cAMP and PKA activity, reduce intrinsic membrane excitability by a mechanism that involves a reduction in $I_{\mathrm{Na}}$ and a concomitant increase in the threshold for AP firing. The time course of this mechanism is rapid, indicative that the site of modulation is outside the cell nucleus. Such a mechanism is clearly advantageous for developing neurons that undoubtedly must face rapidly changing levels of synaptic excitation as they integrate into and stabilize the circuits that ultimately will coordinate appropriate behavior in the adult.

To adjust membrane excitability in the face of changing exposure to synaptic excitation, it is implicit that a postsynaptic cell must be able to monitor the sum total of its depolarization. This measure then must be transduced in to a molecular signal that, in turn, must interact with specific effector molecules to bring about the necessary changes in membrane excitability. In the two genetic backgrounds ( $d n c$ and ace) used in this study in which synaptic excitation is increased, the RMP of aCC/RP2 is elevated significantly. It cannot be stated yet, however, whether this increase in RMP is in itself sufficient to mediate the change in excitability observed in these neurons. Similarly, it also remains to be determined why the RMP is elevated in these backgrounds.
A

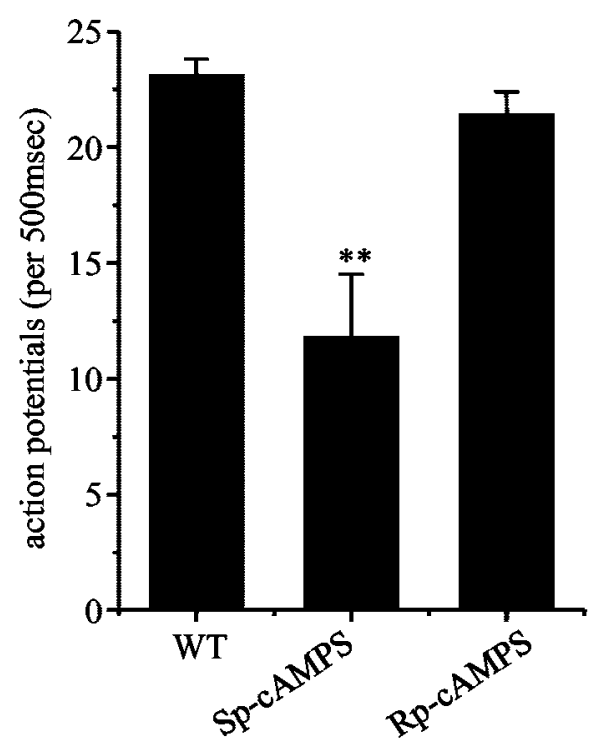

B

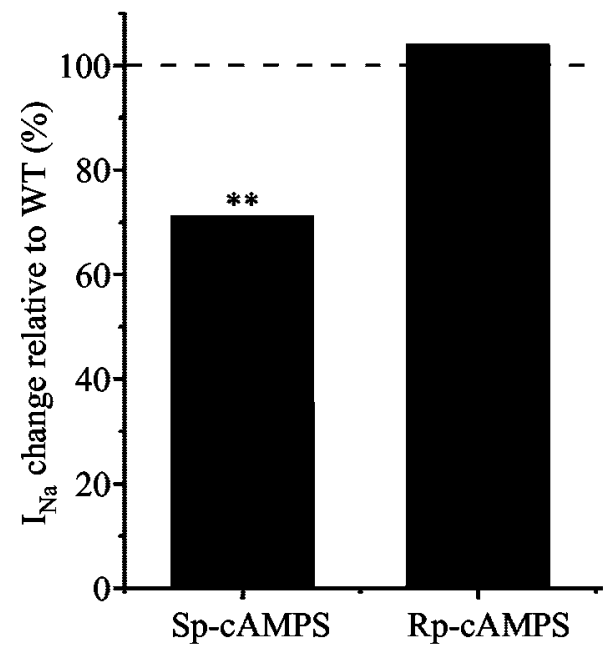

C

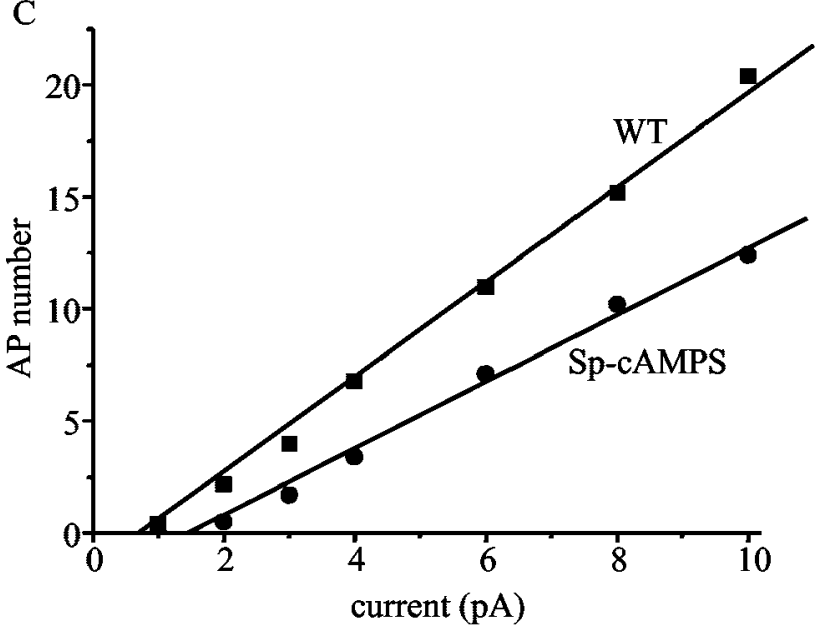

Figure 7. Regulation of membrane excitability is rapid. $A$, Exposure of aCC/RP2 to a membrane-permeant activator of PKA (Sp-CAMPS; $0.5 \mathrm{~mm} / 5 \mathrm{~min}$ ) is sufficient to induce a significant reduction in the number of $A P s$ fired in response to an injection of depolarizing current (10 pA/500 msec). Inhibition of PKA by using membrane-permeant Rp-cAMPS ( $0.5 \mathrm{~mm} / 5 \mathrm{~min})$ was without effect. $B$, Exposure to the PKA activator Sp-cAMPS $(0.5 \mathrm{~mm} / 5 \mathrm{~min})$ is also sufficient to reduce $I_{\mathrm{Na}}$ significantly as compared with control (dashed line; normalized to $100 \% ; 20.0 \pm$ $1.7 \mathrm{vs} 28.0 \pm 2.6 \mathrm{pA} / \mathrm{pF}$, respectively). Exposure to Rp-cAMPS did not affect $I_{\mathrm{Na}}{ }^{* *} p \leq 0.01 . \mathrm{C}$, Exposure of aCC/RP2 to Sp-CAMPS $(0.5 \mathrm{~mm} / 5 \mathrm{~min})$ also increased the current required to elicit a comparable number of APs relative to WT. 
Clearly, although any increase in exposure to excitatory neurotransmitter is likely to affect the depolarized state of a postsynaptic target, it might be expected that, between bouts of neurotransmitter release, RMP would return to control levels. It must be borne in mind, however, that the electrotonic geometry of aCC/ RP2 is not ideal in the sense that the cell body (from where recordings are made) is a considerable distance from both the spike initiation zone and dendritic arbor and, moreover, is separated from these sites by a relatively narrow neurite. Thus although the voltage-clamp determination of $I_{\mathrm{K}}$ shows a small, but nonsignificant, reduction in current density at the cell body, this measurement almost certainly does not reflect fully the situation in the dendrites, where the reduction in $I_{\mathrm{K}}$ could be more significant. In such a scenario any excitatory influences, such as ACh release from presynaptic terminals, might be predicted to result in greater depolarization. Moreover, if outward leak current is reduced similarly, such increased depolarization might have the potential to elevate RMP tonically.

Regardless of the precise identity of the monitor of depolarization, to effect appropriate change in membrane excitability, one or more conductances must be altered in response to changing synaptic excitation. This study clearly identifies the voltagegated $\mathrm{Na}^{+}$channel as a key target of PKA activity to mediate a reduction in membrane excitability in the face of increased synaptic excitation. It remains to be determined, however, whether a reduction in $I_{\mathrm{Na}}$ alone can account fully for the reduction in associated excitability in aCC/RP2. Indeed, comparison between the effect on excitability produced by TTX with that observed in both $d n c$ and ace is indicative that other factors may be influenced by activity. This is because, although the level of TTX that was used reduced $I_{\mathrm{Na}}$ by a comparable amount, the reduction in excitability that was observed was greater with TTX. Clearly, a better understanding of the contribution of all of the ionic conductances in aCC/RP2 to AP generation and of how they are influenced by activity will be required before a better understanding for this apparent discrepancy is possible.

Regulation by PKA suggests that the Drosophila neuronal $\mathrm{Na}^{+}$ channel may be similar to rat neuronal $\mathrm{Na}^{+}$channels that are also known to be modulated in this manner (Costa and Catterall, 1984; Offord and Catterall, 1989; Gershon et al., 1992). Sodium channels found in rat brain contain five putative PKA consensus sites in the cytoplasmic linker that connects domains I and II (Murphy et al., 1993). Site-directed mutagenesis of each site in turn indicates that phosphorylation reduces $I_{\mathrm{Na}}$ principally by introducing a negative charge at serine 573 (Smith and Goldin, 1997). Phosphorylation at any of the other PKA consensus sites results in similar, but diminished, reductions in $I_{\mathrm{Na}}$, indicative of some degree of positional specificity. Drosophila neurons, by comparison, express only one functional $\mathrm{Na}^{+}$channel during early stages of embryonic and larval development (as used in this study). This $\mathrm{Na}^{+}$channel, encoded by the paralytic ( para) gene, similarly contains PKA consensus sites within the first intracellular loop (Loughney et al., 1989). Indeed, one such site is known to be spliced alternatively, perhaps underscoring the importance of this site and its possible involvement in the regulation of $\mathrm{Na}^{+}$ conductance in Drosophila neurons (O'Dowd et al., 1995).

How phosphorylation of $\mathrm{Na}^{+}$channels results in reduced current amplitude is unknown. Similar to the effect observed in the present study, the reduction in current resulting from phosphorylation of the rat neuronal IIA $\mathrm{Na}^{+}$channel is equally rapid, occurring within 5 min after PKA induction. Moreover, it is also reversible, taking $\sim 1 \mathrm{hr}$ to return to baseline levels. Both time courses are consistent with post-translational mechanisms and do not require mechanisms reliant on altered gene expression (Smith and Goldin, 1997). A consistency to emerge from this and previous studies is that the reduction in $I_{\mathrm{Na}}$ does not appear to result from changes in the voltage dependence of activation, steady-state inactivation, or the number of functional channels present in the membrane (Li et al., 1992; Wicher, 2001). Where more detailed experiments have been conducted, single channel recordings indicate that cAMP-dependent phosphorylation of rat brain IIA $\mathrm{Na}^{+}$channels reduces current amplitude by lowering the open probability of single channels during depolarization (Li et al., 1992). Such a mechanism has been predicted to increase the threshold of AP firing, which is precisely what is observed in the present study. Moreover, computer modeling of similar modest decreases in $I_{\mathrm{Na}}$ that reduced the magnitude of this current by the same amount seen in this study predicts that, in addition to increasing AP threshold, the delay between successive APs also will be increased significantly, whereas effects on individual AP amplitude and duration will be more subtle (Gershon et al., 1992). These in silico predictions are validated by the present study.

A diverse range of voltage- and ligand-gated ion channels is known to be modulated by cAMP/PKA phosphorylation (Levitan, 1999; Catterall, 2000). In addition to neuronal $\mathrm{Na}^{+}$channels, one notable example is the large-conductance $\mathrm{Ca}^{2+}$ dependent $\mathrm{K}^{+}$channels that respond to both membrane voltage and intracellular $\mathrm{Ca}^{2+}$ (Atkinson et al., 1991; Adelman et al., 1992). The $\mathrm{K}^{+}$current carried by one such channel, that encoded by the Drosophila slowpoke gene, is reduced significantly when this channel is coexpressed with activated PKA in mammalian tsA201 cells (Zhou et al., 2002). This effect has been attributed to a decrease in sensitivity to both membrane voltage and to intracellular $\mathrm{Ca}^{2+}$ in the presence of activated PKA. The present study provides sufficient evidence to suggest that such regulation indeed may occur in vivo. The simultaneous reductions in both $I_{\mathrm{Na}}$ and $I_{\mathrm{K}(\mathrm{Ca})}$ that would be the predicted outcome of such regulation is, at least initially, counter-intuitive in that each effect in isolation would be expected to oppose the other. However, contributions of ion channel activity to endogenous excitability cannot be considered in isolation; whereas a reduction in $I_{\mathrm{Na}}$ clearly results in a decrease in excitability, a decrease in $I_{\mathrm{K}(\mathrm{Ca})}$ might underlie the increased RMP that has been observed. In this regard it may be significant that, in the absence of synaptic excitation, aCC/RP2 respond by increasing both $I_{\mathrm{Na}}$ and $I_{\mathrm{K}}$ (Baines et al., 2001).

Ligand-gated channels, such as the Drosophila L-glutamate receptor DGluRIIA, also are modulated by PKA activity. Phosphorylation of DGluRIIA by PKA results in a reduction of quantal size, whereas inhibition of PKA evokes a compensatory increase in quantal size, indicative that DGluRIIA is substantially phosphorylated in its basal state (Davis et al., 1998). By comparison, inhibition of PKA activity in aCC/RP2 does not result in a corresponding increase in $I_{\mathrm{Na}}$ in these neurons, although it is sufficient to block an activity-dependent decrease in this current. The apparent lack of effect of inhibiting PKA in WT neurons is intriguing, particularly in the light of the fact that depriving these same neurons of synaptic excitation during embryonic development via blockade of neurotransmitter release is sufficient to increase $I_{\mathrm{Na}}$ and membrane excitability (Baines et al., 2001). Preliminary analysis under such conditions suggests that neurons deprived of synaptic excitation respond by upregulating the transcription of para (C. Mee and R. A. Baines, unpublished data). Thus it would seem that Drosophila motoneurons are capable of using differing mechanisms to respond to opposite changes in synaptic excitation: post-translational phosphorylation of Para 
when excitation increases and upregulation of para gene expression when synaptic excitation is too low. Loss of synaptic input would be expected to depress intracellular $\mathrm{Ca}^{2+}$ levels, and it could be that the altered levels of $\mathrm{Ca}^{2+}$ lead to changes in gene expression (see Bito, 1998) whereas increased $\mathrm{Ca}^{2+}$ would increase activity of the type $\mathrm{I} \mathrm{Ca}^{2+} /$ calmodulin-dependent adenylate cyclase encoded by rut (Zars et al., 2000). This conclusion should be treated with some caution, however, because selective dephosphorylation of specific PKA consensus sites by identified phosphatases also is implicated to control the level of phosphorylation of rat $\mathrm{Na}^{+}$channels (Murphy et al., 1993). The involvement of phosphatases in regulation of $I_{\mathrm{Na}}$ in aCC/RP2 has yet to be determined.

\section{References}

Adelman JP, Shen K-Z, Kavanaugh MP, Warren RA, Wu Y-N, Lagrutta A, Bond CT, North RA (1992) Calcium-activated potassium channels expressed from cloned complementary DNAs. Neuron 9:209-216.

Atkinson NS, Robertson GA, Ganetzky B (1991) A component of calciumactivated potassium channels encoded by the Drosophila slo locus. Science 253:551-555.

Baines RA, Bate M (1998) Electrophysiological development of central neurons in the Drosophila embryo. J Neurosci 18:4673-4683.

Baines RA, Robinson SG, Fujioka M, Jaynes JB, Bate M (1999) Postsynaptic vesicle release is essential for synaptogenesis in Drosophila. Curr Biol 9:1267-1270.

Baines RA, Uhler JP, Thompson A, Sweeney ST, Bate M (2001) Altered electrical properties in Drosophila neurons developing without synaptic transmission. J Neurosci 21:1523-1531.

Baines RA, Seugnet L, Thompson A, Salvaterra PM, Bate M (2002) Regulation of synaptic connectivity: levels of Fasciclin II influence synaptic growth in the Drosophila CNS. J Neurosci 22:6587-6595.

Bito H (1998) The role of calcium in activity-dependent neuronal gene expression. Cell Calcium 23:143-150.

Cameron JS, Dryer L, Dryer SE (2001) $\beta$-Neuregulin-1 is required for the in vivo development of functional $\mathrm{Ca}^{2+}$-activated $\mathrm{K}^{+}$channels in parasympathetic neurons. Proc Natl Acad Sci USA 98:2832-2836.

Catterall WA (2000) From ionic currents to molecular mechanism: the structure and function of voltage-gated sodium channels. Neuron 26:13-25.

Costa MR, Catterall WA (1984) Cyclic AMP-dependent phosphorylation of the alpha subunit of the sodium channel in synaptic nerve ending particles. J Biol Chem 259:8210-8218.

Davis GW, Bezprozvanny I (2001) Maintaining the stability of neural function: a homeostatic hypothesis. Annu Rev Physiol 63:847-869.

Davis GW, DiAntonio A, Petersen SA, Goodman CS (1998) Postsynaptic PKA controls quantal size and reveals a retrograde signal that regulates presynaptic transmitter release in Drosophila. Neuron 20:305-315.

Davis RL, Cherry J, Dauwalder B, Han PL, Skoulakis E (1995) The cyclic AMP system and Drosophila learning. Mol Cell Biochem 149/150:271-278.

Desai NS, Rutherford L, Turrigiano GG (1999) Plasticity in the intrinsic excitability of cortical pyramidal neurons. Nat Neurosci 2:515-520.

DiAntonio A, Petersen SA, Heckmann M, Goodman CS (1999) Glutamate receptor expression regulates quantal size and quantal content at the Drosophila neuromuscular junction. J Neurosci 19:3023-3032.

Dudai Y, Jan YN, Byers D, Quinn WG, Benzer S (1976) dunce, a mutant of Drosophila deficient in learning. Proc Natl Acad Sci USA 73:1684-1688.

Fujioka M, Emi-Sarker Y, Yusibova GL, Goto T, Jaynes JB (1999) Analysis of an even-skipped rescue transgene reveals both composite and discrete neuronal and early blastoderm enhancers, and multi-stripe positioning by gap gene repressor gradients. Development 126:2527-2538.

Gershon E, Weigl L, Lotan I, Schreibmayer W, Dascal N (1992) Protein kinase A reduces voltage-dependent $\mathrm{Na}^{+}$current in Xenopus oocytes. J Neurosci 12:3743-3752.

Golowasch J, Abbot LF, Marder E (1999) Activity-dependent regulation of potassium currents in an identified neuron of the stomatogastric ganglion of the crab, Cancer borealis. J Neurosci 19:RC33(1-5).

Greenspan RJ (1980) Mutations of choline acetyltransferase and associated neural defects in Drosophila melanogaster. J Comp Physiol [A] 137:83-92.

Kiger Jr JA, Eklund JL, Younger SH, O’Kane CJ (1999) Transgenic inhibitors identify two roles for protein kinase A in Drosophila development. Genetics 152:281-290.

Levitan IB (1999) Modulation of ion channels by protein phosphorylation. How the brain works. Adv Second Messenger Phosphoprotein Res 33:3-22.

Li M, West JW, Lai Y, Scheuer T, Catterall WA (1992) Functional modulation of brain sodium channels by cAMP-dependent phosphorylation. Neuron 8:1151-1159.

Liu Z, Golowasch J, Marder E, Abbott LF (1998) A model neuron with activity-dependent conductances regulated by multiple calcium sensors. J Neurosci 18:2309-2320.

Loughney K, Kreber R, Ganetzky B (1989) Molecular analysis of the para locus, a sodium channel gene in Drosophila. Cell 58:1143-1154.

Murphy BJ, Rossie S, De Jongh KS, Catterall (1993) Identification of sites of selective phosphorylation and dephosphorylation of the rat brain $\mathrm{Na}^{+}$ channel $\alpha$-subunit by cAMP-dependent protein kinase and protein phosphatases. J Biol Chem 268:27355-27362.

Nick TA, Ribera AB (2000) Synaptic activity modulates presynaptic excitability. Nat Neurosci 3:142-149.

O'Brien R, Kambol S, Ehlers MD, Rosen KR, Kischback GD, Huganir RL (1998) Activity-dependent modulation of synaptic AMPA receptor accumulation. Neuron 21:1067-1078.

O'Dowd DK, Gee JR, Smith MA (1995) Sodium current density correlates with expression of specific alternatively spliced sodium channel mRNAs in single neurons. J Neurosci 15:4005-4012.

Offord J, Catterall WA (1989) Electrical activity, cAMP, and cytosolic calcium regulate mRNA encoding sodium channel $\alpha$-subunits in rat muscle cells. Neuron 2:1447-1452.

Paradis S, Sweeney ST, Davis GW (2001) Homeostatic control of presynaptic release is triggered by postsynaptic membrane depolarization. Neuron 30:737-749.

Smith RD, Goldin AL (1997) Phosphorylation at a single site in the rat brain sodium channel is necessary and sufficient for current reduction by protein kinase A. J Neurosci 17:6086-6093.

Spitzer NC, Vincent A, Lautermilch NJ (2000) Differentiation of electrical excitability in motoneurons. Brain Res Bull 53:547-552.

Spitzer NC, Kingston PA, Manning Jr TJ, Conklin MW (2002) Outside and in: development of neuronal excitability. Curr Opin Neurobiol 12:315-323.

Turrigiano GG (1999) Homeostatic plasticity in neural networks: the more things change, the more they stay the same. Trends Neurosci 22:221-227.

Turrigiano GG, Nelson SB (2000) Hebb and homeostasis in neuronal plasticity. Curr Opin Neurobiol 10:358-364.

Turrigiano GG, Abbot LF, Marder E (1994) Activity-dependent changes in the intrinsic properties of cultured neurons. Science 264:974-977.

Turrigiano GG, LeMasson G, Marder E (1995) Selective regulation of current densities underlies spontaneous changes in activity in cultured neurons. J Neurosci 15:3640-3652.

Turrigiano GG, Leslie KR, Desai NS, Rutherford LC, Nelson SB (1998) Activity-dependent scaling of quantal amplitude in neocortical neurons. Nature 391:892-896.

Wicher D (2001) Peptidergic modulation of an insect $\mathrm{Na}^{+}$current: role of protein kinase A and protein kinase C. J Neurophysiol 85:374-383.

Xie H, Ziskind-Conhaim L (1995) Electrical properties of motoneurons in the spinal cord of rat embryos. Dev Biol 128:21-29.

Zars T, Wolf R, Davis R, Heisenberg M (2000) Tissue-specific expression of a type I adenylyl cyclase rescues the rutabaga mutant memory defect: in search of the engram. Learn Mem 7:18-31.

Zhong Y, Wu C-F (1991) Altered synaptic plasticity in Drosophila memory mutants with a defective cyclic AMP cascade. Science 251:198-201.

Zhou Y, Wang J, Wen H, Kucherovsky O, Levitan IB (2002) Modulation of Drosophila Slowpoke calcium-dependent potassium channel activity by bound protein kinase A catalytic subunit. J Neurosci 22:3855-3863. 